\title{
NUMERICAL ANALYSIS OF AERODYNAMIC CHARACTERISTICS OF A OF HIGH-SPEED CAR WITH MOVABLE BODYWORK ELEMENTS
}

\begin{abstract}
This paper presents the results of numerical analysis of aerodynamic characteristics of a sports car equipped with movable aerodynamic elements. The effects of size, shape, position, angle of inclination of the moving flaps on the aerodynamic downforce and aerodynamic drag forces acting on the vehicle were investigated. The calculations were performed with the help of the ANSYS-Fluent CFD software. The transient flow of incompressible fluid around the car body with moving flaps, with modeled turbulence (model Spalart-Allmaras or SAS), was simulated. The paper presents examples of effective flap configuration, and the example of configuration which does not generate aerodynamic downforce. One compares the change in the forces generated at different angles of flap opening, pressure distribution, and visualization of streamlines around the body. There are shown the physical reasons for the observed abnormal characteristics of some flap configurations. The results of calculations are presented in the form of pressure contours, pathlines, and force changes in the function of the angle of flap rotation. There is also presented estimated practical suitability of particular flap configurations for controlling the high-speed car stability and performance.
\end{abstract}

\section{Introduction}

Modern cars are well designed in terms of aerodynamic shapes of the body and are generally characterized by low coefficients of aerodynamic drag and low coefficients of lift. Such properties are not sufficient for fast cars and GT cars. Fast cornering and effective braking at high speeds require slightly different aerodynamic characteristics. In variable road conditions, the car body is exposed to various types of forces $[1,4,5,6,7]$. They may originate from road irregularities, maneuvers made by the vehicle, aerodynamic forces caused by the motion close to other vehicles, changing weather conditions - especially

* Institute of Aeronautics and Applied Mechanics, Warsaw University of Technology, 24 Nowowiejska,00-665 Warsaw, Poland; E-mail: jpie@meil.pw.edu.pl 
wind energy, variable configuration of the environment (driving over bridges, overpasses, hills, canyons, etc.). Any change in these forces requires some driver's reaction. In the case of existence of combination of several external factors, drivers reactions may be delayed or incorrect. Hence, there is the tendency of introducing legislations in the European Union requiring automakers to equip cars with assistance systems such as ABS, ESP, BAS, ACC. These systems control braking force or the driving force for each wheel of the vehicle. However, to improve the stability of the vehicle, the aerodynamic forces should be used. The system using the aerodynamic element has a number of advantages. The main advantage is that the forces are independent of the state of the road surface. They work well even when the friction between the tires and the road is small. Generation of aerodynamic forces does not require any increase in the vehicle mass, and therefore it does not increase the inertia forces. The aerodynamic forces depend on the square of the velocity, and thus are large when the danger of losing control of the vehicle is high.

When driving conditions are changing, the best solution is to change and adapt aerodynamic characteristics of the car body $[11,13]$. When driving fast on the straights, the car should have a minimal aerodynamic drag, and the downforce doesn't need to be large. When braking, the car should have a significant aerodynamic drag and should produce a greater downforce. The fast cornering and driving through curves requires high value of aerodynamic downforce. The moveable aerodynamic parts of the car body can be the solution that allows for to changing the established characteristics of the car [13]. The forced stall is yet another way of changing aerodynamic characteristics of the fast cars [14], In the world of motorsport and prototypes, the movable aerodynamic elements have been used for many years. The first movable elements used in racing cars have shown their advantages, but the flaws in their design led to some spectacular accidents, and consequently, one introduced changes in regulations precluding their use.

An example of the test platform with moving elements in a car body is the prototype of Mitsubishi HSR II shown in Fig. 1 [11]. The car has a very low drag coefficient of $\mathrm{Cd}=0.2$. It has also a number of moving aerodynamic parts: a movable front spoiler, retractable wings on the side walls and movable flaps on the back, pivoted independently.

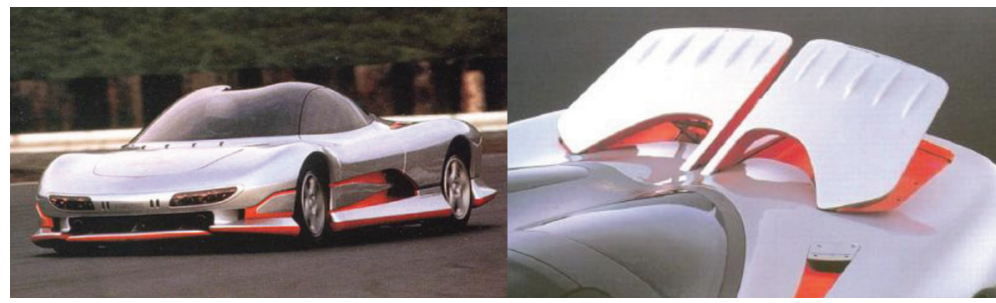

Fig. 1. Mitsubishi HSR II general view - left, flaps in extended position - right 
The shape of the car was changed by the driver. He activated servomechanisms changing position of movable aerodynamic elements installed on the car body. During acceleration, the front spoiler was lowered. During braking, the front spoiler and front panels extended and flaps were set at an angle of $30^{\circ}$. The extended front spoiler and the side wings increased the drag coefficient by 0.01 and increased the downforce coefficient to 0.025 . The raised rear flaps set at an angle of $30^{\circ}$ resulted in the increase of drag coefficient $\mathrm{Cd}$ to 0.21 , and the increase of the downforce coefficient $\mathrm{Cl}$ to 0.42 . During cornering, only the elements on the inside of the turn were activated, the front spoiler was lowered, the rear flap inside the curve was set at an angle of $20^{\circ}$. During cornering, unsymmetrical swinging flaps, increased the aerodynamic downforce on the inside of the vehicle to equalize the internal and external tire loads. At the same time, $\mathrm{Cx}$ was increased by 0.09 , and the downforce coefficient increased by 0.13 .

The positive impact of movable aerodynamic elements on the dynamics of the vehicle and its safety is commonly known [6, 7, 11]. Air brakes reduce the braking distance, especially when braking from high speeds, provide downforce acting on the rear axle, improve the dynamic axle load distribution, ensure predictable and repeatable behaviour of the vehicle during braking, reduce the need for twist angles of the steering wheel required for correction of the car path.

In many designs, fast sports car or GT cars use movable aerodynamic elements.

\section{Effect of aerodynamics during acceleration}

During acceleration, the most important, decisive factors are the tires, good aerodynamics and the engine power. The driving force on the wheels, which depends on the load on tires including aerodynamic downforce, and tire adhesion, must balance the inertia forces and aerodynamic drag forces. During the acceleration of a car, there are two limitations. The first one is the restriction on the power transmitted by the tires at the contact with the road. The second is the power generated by the engine. At low speed, the traction is limited by the wheel slip. The driver cannot therefore use the full power of the engine. The high speed is limited by the engine power. In the first few seconds of the vehicle acceleration with additional aerodynamic elements, the resulting aerodynamic downforce can increase the tire load in contact with the road, so one may give more torque and use more power from the engine to achieve greater acceleration. When accelerating the vehicle, the most important thing at the initial section of the track is to have a good tire grip and high aerodynamic downforce. The cars with high aerodynamic downforce always gain an advantage, even though having a higher drag coefficient. The impact of the 
good tire grip can be heightened by a high downforce value. The engine power becomes crucial only at highest speeds.

With the aerodynamic downforce, car can quickly accelerate to a high speed, but further acceleration and the speed increase is limited by the aerodynamic drag. When starting, the car should have moving flaps opened to have the largest possible downforce at the beginning of the movement. Gradually, during further acceleration, the flap should be closed to reduce the aerodynamic drag of the vehicle at higher speeds, otherwise the acceleration and the top speed would be limited.

\section{Effect of aerodynamics during braking}

The maximum braking force transmitted by the tire depends on the downforce and the coefficient of tires adhesion. The cars with additional aerodynamic components producing high downforce at high speeds can realize greater braking power. At high downforce values, the braking efficiency is higher. However, the reduction of car's speed during braking also reduces the aerodynamic downforce and reduces the tire grip limit, the effect of which should be considered when the brake foot-lever is actuated.

During braking, the inertia force counteracts the forces of aerodynamic drag and the tire reaction force, which is dependent on vehicle weight, tire grip and the aerodynamic downforce. When braking from high speeds, the operation of mechanical brakes is also supported by aero-braking. Aerodynamic braking has a very short duration, because it is limited to the time when the speed is high. An intense aero braking exists only in the first 2-3 seconds, because after that time, due to car speed drop, there occurs a large decrease in aerodynamic drag and downforce. To take advantage of aerodynamic downforce under braking, the driver's response must to be very fast and done in the early stages of braking. The driver must apply a large force on the brake foot-lever in order to achieve greater value of deceleration during braking. The aerodynamic drag of the car provides its own braking force that improves the deceleration so the greatest deceleration during the initial braking phase could be achieved by cars with the greatest value of aerodynamic downforce and a high value of aerodynamic drag.

During braking and the resulting reduction of car velocity, the aerodynamic forces rapidly decrease. For a car with a high aerodynamic downforce improving operation of mechanical brakes and cars using aerodynamic braking stopping force during braking decreases rapidly, but the car stops quickly. Such a car has the shortest braking distances. Aerodynamic braking effect generating also load transfer to the rear axis increases additionally the strength of mechanical brakes, but only in a short period of time at the beginning of brak- 
ing. The car's downforce during deceleration is characterized by a large speed decline at initiation of braking. Generally, vehicles with high aerodynamic downforce stop faster and on a shorter distance.

During the race, the cars frequently only reduce their speed before entering a turn. The cars with aerodynamic elements can begin braking later than ordinary cars. The effect of the additional aerodynamic elements generating downforce can be clearly seen while driving on a track with lots of corners requiring frequent braking. The cars using the aerodynamic downforce are also more stable in cornering.

The air brakes are used for reduction of the car's speed. The elements that are expected to increase the car's aerodynamic drag should have a high coefficient of resistance and a large surface area to have CdA value as large as possible. The rules of races typically prohibit the use of moveable aerodynamic elements.

In the fifties, Mercedes used a plate of $0.7 \mathrm{~m}^{2}$ at the rear part of the vehicle tilted by a hydraulic cylinder as an airbrake at high speed $[3,11]$. At a speed of $300 \mathrm{~km} / \mathrm{h}$, the braking flap gave a value of $4850 \mathrm{~N}$ of drag force. A movable surface placed on the rear part of the body additionally increased aerodynamic downforce of the rear axle and, at the same time, relieved the front axle. The rear axle downforce increased braking efficiency of the rear axle brakes.

Additionally, many later models of Mercedes cars and sports prototypes of other firms used moveable aerodynamic as air brakes when braking at high speeds. Such modern cars like McLaren F1, Mitsubishi HSR and the Bugatti Veyron have air brakes.

\section{Effect of aerodynamics during cornering}

When cornering, each vehicle has a critical speed related to road curvature. When cornering, the force of inertia, directed outward the curve, must be balanced by the lateral forces generated by the tires. The force transmitted by the tire depends on the vertical component of the load force acting on the tire, which consists of the weight of the vehicle and the aerodynamic downforce. The increase in the aerodynamic downforce increases the cornering speed limit. When the car drives around a curve, beyond a certain critical speed the tire starts to slip. If the tire is loaded with a greater downforce, a greater lateral force can be generated, and the slip occurs at a higher speed. The increase in downforce by increasing the weight of the vehicle does not improve the situation, because the lateral inertia force on the curve rises by the same amount as the tire contact force, and the critical speed remains the same. The vertical tire load can be increased by using the aerodynamic forces, since they increase the lateral force generated by the tire, but not increase the centrifugal force. The 
aerodynamic downforce can have a big impact on the cornering ability and the achieved maximum speed while driving around a curve.

\section{The assumptions used in the simulation}

The aim of this study was to analyze the influence of the shape, location and method of geometry changes of a variety of deflected flaps on the generated aerodynamic forces. Since the operation of such flaps may depend strongly on the shape of the body on which they are placed, a very simple body shape was selected to omit possible interferences with a too complicated geometry, for example with the wake behind the side mirrors (see Fig. 2). Due to this assumption, all the results should be only treated as a demonstration ones showing and explaining physical processes taking place during car's operation, but not as the data directly applicable to different car geometries.

The analysis and numerical simulation has been done using the ANSYS-Fluent $[2,8,9,10]$. The basis for the calculation was the geometry of the vehicle, similar in shape to those used in group $\mathrm{C}$ and race cars used on the Le Mans track. The basic geometry of the body has not been changed during the calculation of the investigated flap versions. The car bodies differed only in the flap dimensions, the place of their location, and the location of the flap's axis of rotation. Figure 2 shows the basic geometry of the body of the vehicle used in the flow simulations.

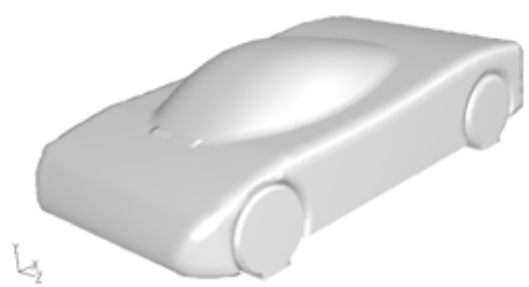

Fig. 2 Basic geometry of the car analyzed

The general dimensions of the flow domain are presented in Fig. 3. The domain size was defined on the basis of the existing standards [8] and our own experience $[12,14]$.

$8 \mathrm{xL}$

$8 \mathrm{xH}$

$6 \times \mathrm{H}$

$\mathrm{H}$

Fig. 3 General dimensions of the flow domain 
Three main grid areas have been used: the external coarse grid area, the internal box around the car used to utilize a constant denser grid near the car surfaces (see Fig. 4), and the additional area of deforming grid used in the zone occupied by the moving flaps (see Fig. 5). The grid was first created on the surface of the car and then there was formed a spatial mesh around the model within a given area of computing. The grid consisted of different number of nodes and elements dependent on the model. The grid generated in areas occupied by the movable flaps was finer. The grid size was defined on the basis of general rules presented in [8] and on the basis of own experience of the authors $[12,14]$. In the case of symmetric geometry, only a half of the computational domain was used. Consideration of asymmetric flaps required the full domain to be used.

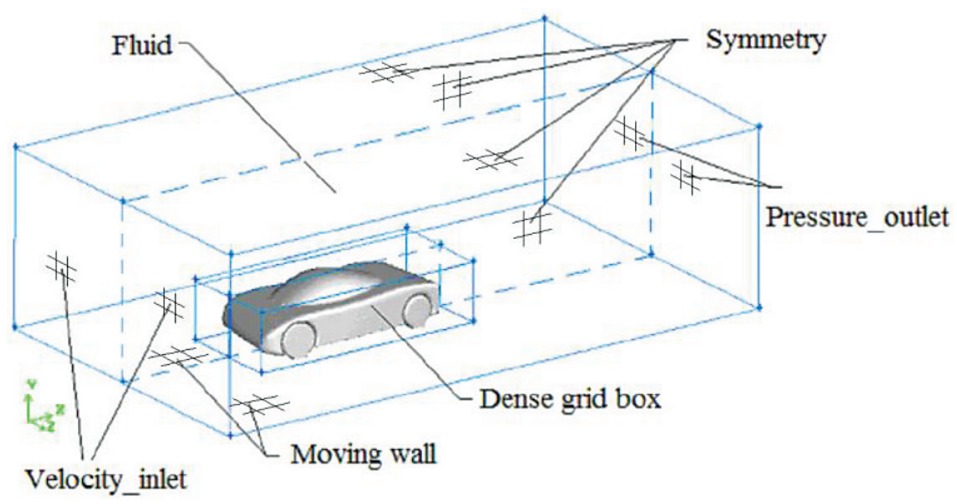

Fig. 4. Sketch of applied boundary conditions
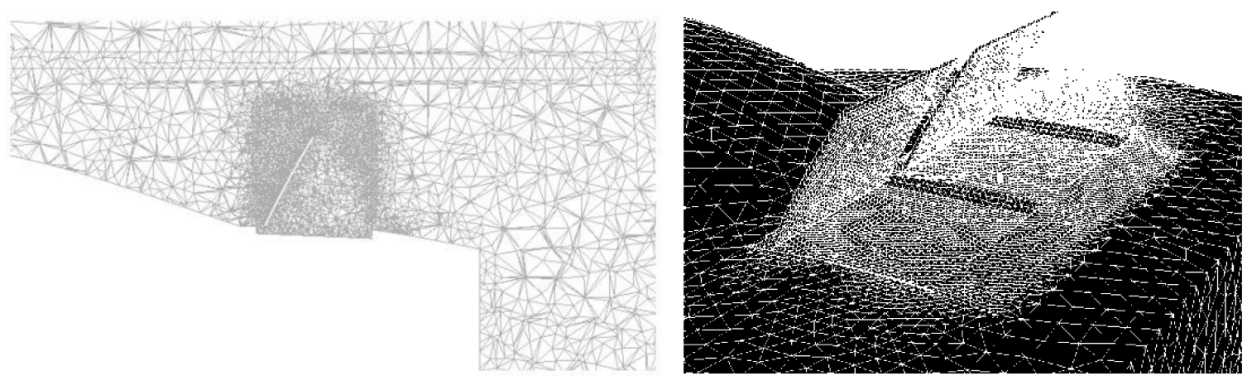

Fig. 5. Example of used grid, denser in deforming grid area

Viscous effects and the impact of turbulence in the boundary layer were addressed through the use of the one-equation Spalart-Allmaras turbulence model or the SAS model. For the calculated cases, the following parameters of the turbulence were used at the inlet to the area of the calculation: the turbulence intensity equal to $2 \%$, and the turbulence dimensional scale equal to $0.005 \mathrm{~m}$. The effect of wheel spin has not been modeled. 
The model of geometry and the mesh, developed in the Gambit, were then exported to the Fluent. The calculations were performed in transient flow mode. At the beginning, the fixed geometry car model was investigated to collect the reference values. Then, the model with individual flap elements was added.

\section{Overview of considered car geometry}

The research began with a study of flow around a fixed basic shape of the car with flaps closed. These results were taken as the reference values. Consequently, the model was modified by placing a variety of flaps in some places on the body. The aim of the study was to investigate the changes in aerodynamic characteristics of the body caused by the use of additional moveable aerodynamic elements.

The analysis of flow area near the vehicle, and the resulting data are presented in the form of distributions of pressure, shear stress on the body surface, and diagrams visualizing the characteristic parameters of the flow. There are also determined and visualized the streamlines allowing for identification of location of separation area, and determination of the recirculation zones behind the vehicle. The aim of this study was to examine the flow process at the time of the flap rotation, to identify characteristic features of the flow field, and to determine the forces acting on the body. Some examples of the analysed flaps geometry are presented in Fig. 6.

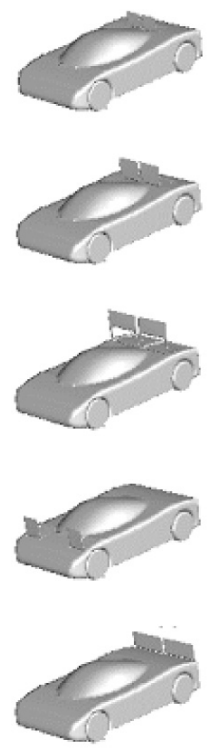

Small movable flaps on the rear part of the body

Big movable flaps on the rear part of the body

Flaps over the body

Movable flaps on the front part of the body

Movable flaps on the rear edge of the body

Fig. 6. Basic types of flaps investigated 


\section{Aerodynamic forces}

During simulations, the aerodynamic forces acting on the car body, being a result of flow around the vehicle, were calculated and the data were stored.

\section{Flow visualization}

The analysis based only on aerodynamic force measurements cannot show the sources and ways of such a force generation. The detailed analysis of the flow gives an opportunity to recognize the areas and reasons for generation of aerodynamic forces acting on the car. The purpose of the analysis based on visualization of the flow is to locate the places where the flow is disturbed. The most important is the nature and the structure of the flow. Visualization of pathlines provides an important information about the flow structure. The areas of streamlined flow, separation and recirculation, vorticity generation can be determined. This gives a more complete picture of the nature of the flow.

\section{Pressure distribution}

Any flow disturbance has a reason. Changes in pressure distribution on the car body surface, as well as formation of pressure gradients affect the character and behavior of the boundary layer. The pressure distributions were visualized on the surface of the vehicle. Based on the pressure contours, the value of the pressure drag and aerodynamic downforce can be determined. The depicted pressure contours on the car body surface show the experienced aerodynamicists the details of flow around a car and clarify its structure.

\section{Simulation results}

Sample plots used in the analysis of the flow, for car with flaps placed just behind the cockpit, will be shown below. The calculation began with the analysis of the opening flaps located on the rear part of the body behind the cockpit. Each flap was opening at a constant speed relative to the axis of rotation defined by the edge of the flap positioned at a distance of $0.58 \mathrm{~m}$ from the rear edge of the car. The flap had rectangular shape with the following dimensions: $0.31 \mathrm{~m}$ width and $0.271 \mathrm{~m}$ height (the surface was equal to $840.1 \mathrm{~cm}^{2}$ ), occupying a quarter of the surface of the tailgate. Exemplary geometry of the flap at full deflection is shown in Fig. 7.

Geometry of the flaps and its position on the body, as well as the changes in distribution of the pressure coefficient during subsequent stages of flap opening are depicted in Fig. 8. When the flaps start to open, a stagnation zone is formed 
on the front surface of the flap. Opening of the flap creates a low pressure area downstream and under the car body near the rear axle. One can notice the strong aerodynamic interaction between various components of the body.

All flaps are placed in shallow cavities in the car body (see Fig. 5), and initially are arranged so that they form a smooth surface on the car body. The flaps rotate relative to the axis located at the front edges of the flaps, in this case.

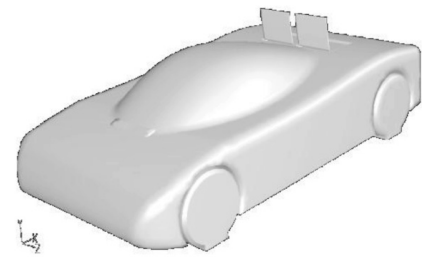

Fig. 7. Basic flaps configuration. The moving flaps located behind the cabin

In Fig. 8 there are depicted pressure contours at the successive phases of the flaps opening. Visible is the gradual pressure increase on the car body in front of the flaps, and pressure reduction behind flaps. A pressure drop is visible in the rear parts of the underbody.
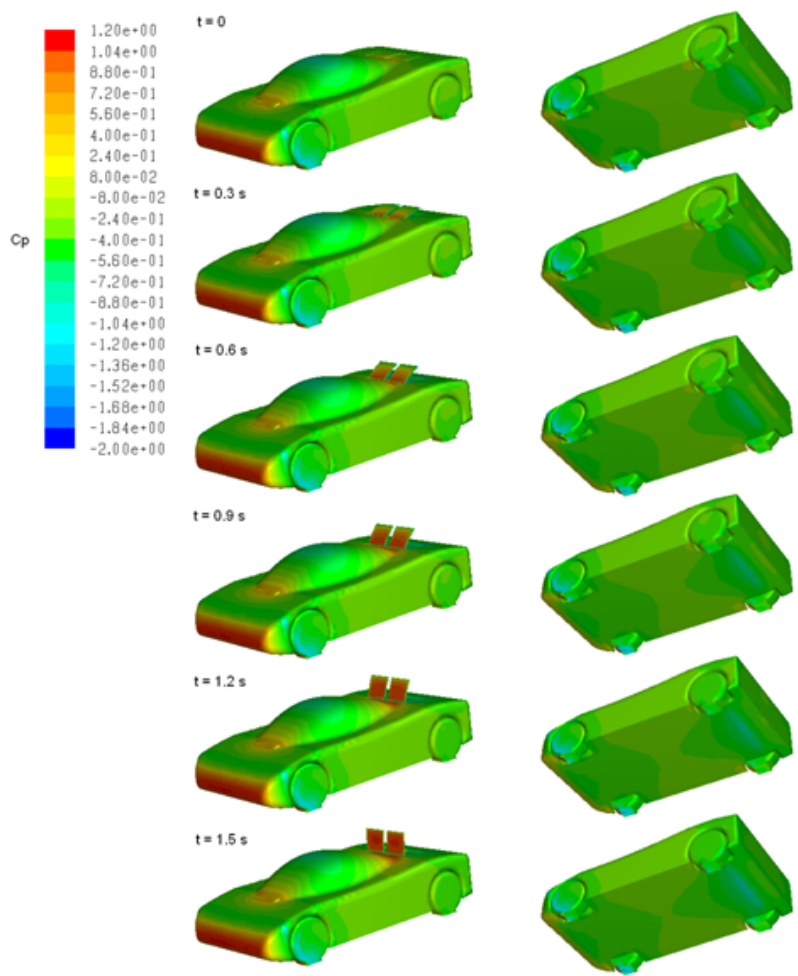

Fig. 8. Visualization of pressure distribution on the body (top and undertray) at successive phases of the flap opening 


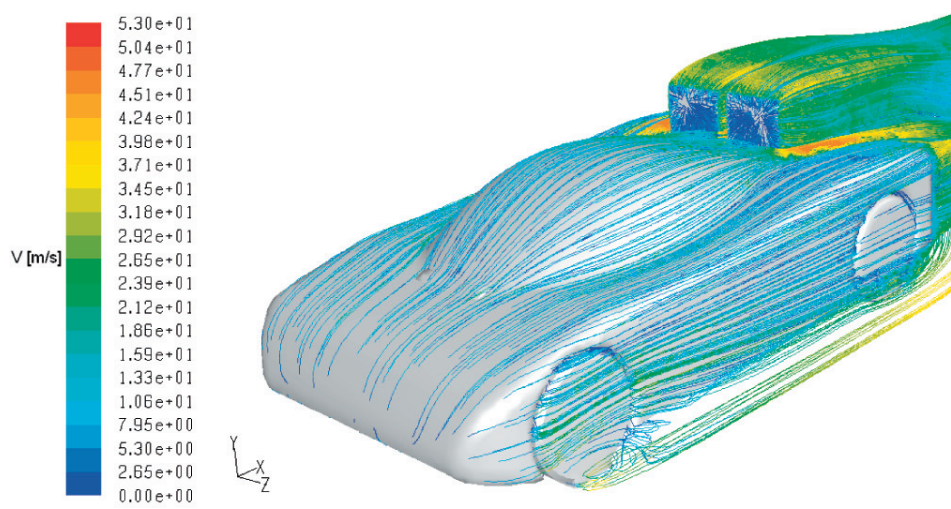

Fig. 9. Streamlines around the car body with flaps fully extended

Figure 9 shows visualization of streamlines around the body with a flaps fully extended. The flow around the car body is very smooth. One can only observe flow separation localized at the edges of flaps.

Figure 10 shows the comparison of pressure distribution in the plane of symmetry in the configuration of flaps opened and closed. There is visible the increase of pressure over a large area in front of the open flaps, and the pressure drop over the body behind flaps. Opening of the flap causes a slight drop in pressure in the underbody. One can noticed an increase in positive pressure in the area in front of the flap, but behind the flap there arrives a great zone of low pressure mitigating generation of the downforce. Pressure distribution on the car symmetry plane, shown in Fig. 10, confirms previous conclusions. Great area of high pressure generated by the flap upstream and low pressure area downstream the flap is typical.

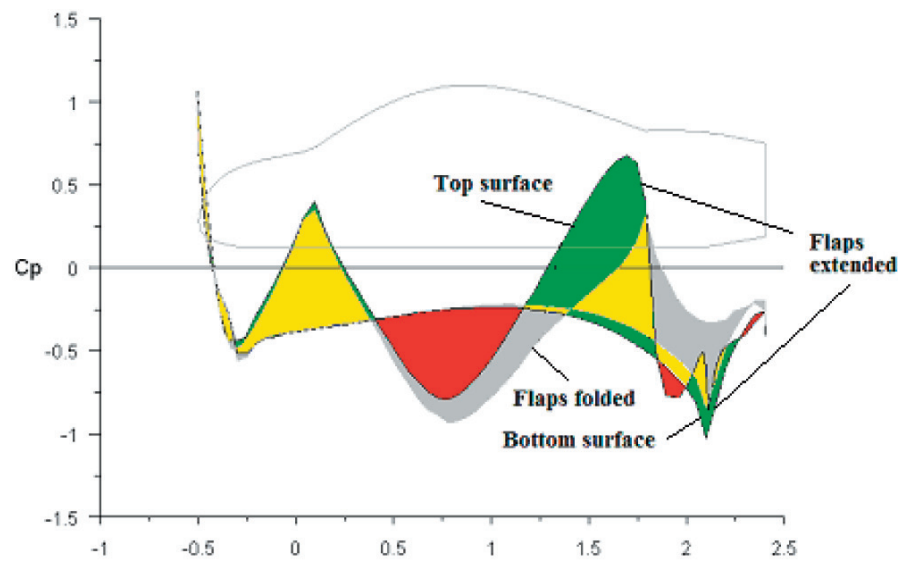

Fig. 10. Comparison of pressure distribution in the plane of symmetry of the vehicle in the configuration of flaps opened and closed 
The analyzed flap position on the car body can suggest that it can operate as an aerodynamic braking device, but is not a preferable as downforce generator, because of the considerable pressure reduction on the car body behind flaps, which neutralizes the increase of positive pressure on the body upstream flaps.

Systematic investigation of very different flap configuration was performed to determine the influence of flap position on the generated downforce and drag. In Fig. 11 there is presented the dependence between the generated lift force and the flap angle rotation for different geometrical configuration of flaps.
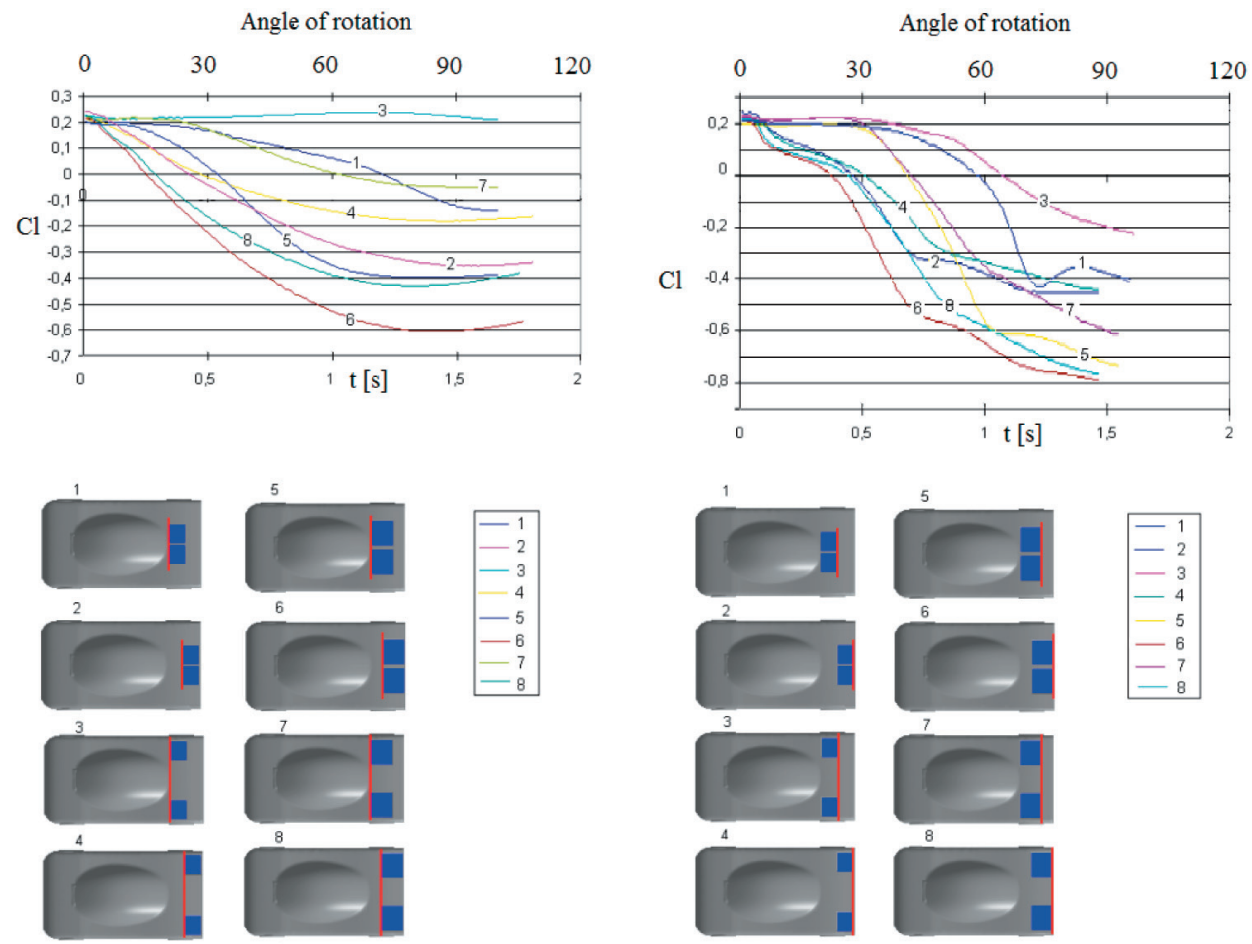

Fig. 11. Comparison of lift generation by different flaps divided into two groups (left sketch - flaps rotating around front edge of the flap, right sketch - flaps rotating around back edge of the flap)

For clarification of flow structure and easier interpretation of data, the investigated flaps were divided into two groups showing different flow feature due to different position of the flap axis of rotation. The charts are reorganized to include only the cases with the same position of the flap rotation axis, separately for front and back axis position.

Figure 11 shows the changes in the coefficients of lift force due to the change of the flap's opening angle. Positive values represent the lift upwards, negative a downforce acting on the road vehicle. While the changes in aerodynamic drag coefficients and their maximum values are similar (see Fig. 12), 
the variation and the extreme values of the lift are significantly different. It is easily to notice that there exist flap configurations generating a high downforce (case 6 and 8), and the configurations which do not generate the downforce at all (case 3).

Opening of the flap increases the pressure on the surface in front of the flap and causes a fall of pressure behind it. Therefore, the most effective are the positions of the flap that provide the largest area of the body in front of it, and the smallest behind it. It appears that the flaps should be placed as close to the end of the body as possible, the axis of rotation should be close to the end of the body, and the flaps should cover the largest width of the body. If they are narrower than the body, they should be placed at some distance from the sides of the body to provide maximum surface area for utilizing the raised pressure generated by the open flaps.

It seems that the position of the axis of flap rotation has a significant impact on the flow structure around the car body, and on its aerodynamic characteristics. Rotation around the axis of the flap on the rear, at the beginning of opening (if the opening angles are small) generates increased pressure under the flap and in front of it. For small opening angles, the flow on the upper surface of the flap is not separated and generates a lift force. At a larger opening angle, flow separation occurs, and the pressure on the flap top surface is not so low.

While the force generated by the pressure increase under the flap is compensated by a similar force acting on the body under the flap, the pressure increase in front of the flap spreads over a large area in front of the flap, moreover, it generates a downforce. Such a configuration appears to be more effective than the configuration in which the axis of flap rotation is located at the front edge of the flap, but only for larger opening angles. In the initial stage of flap opening, up to the opening angle of about 30 degrees, the downforce is not incremented. Downforce generation begins after the angle exceeds a critical angle.

In almost all configurations, one can observe generation of downforce beyond the critical angle of opening. The change in forces is not linearly dependent on the angle of opening. The downforce is always generated, regardless of the size and position of the flap. The function of force change versus rotation angle is strongly non-linear, but the forces are greater than in the case when the axis of rotation is located at the flap front.

In Fig. 12, there is presented the dependence between the generated drag force and the flap angle rotation, for different geometrical configuration of flaps. For clear presentation of drag force generation mechanism, the flaps are divided into two groups: small flaps and big flaps, independent on the position of flap axis of rotation. The course of drag dependence on the flap deflection 

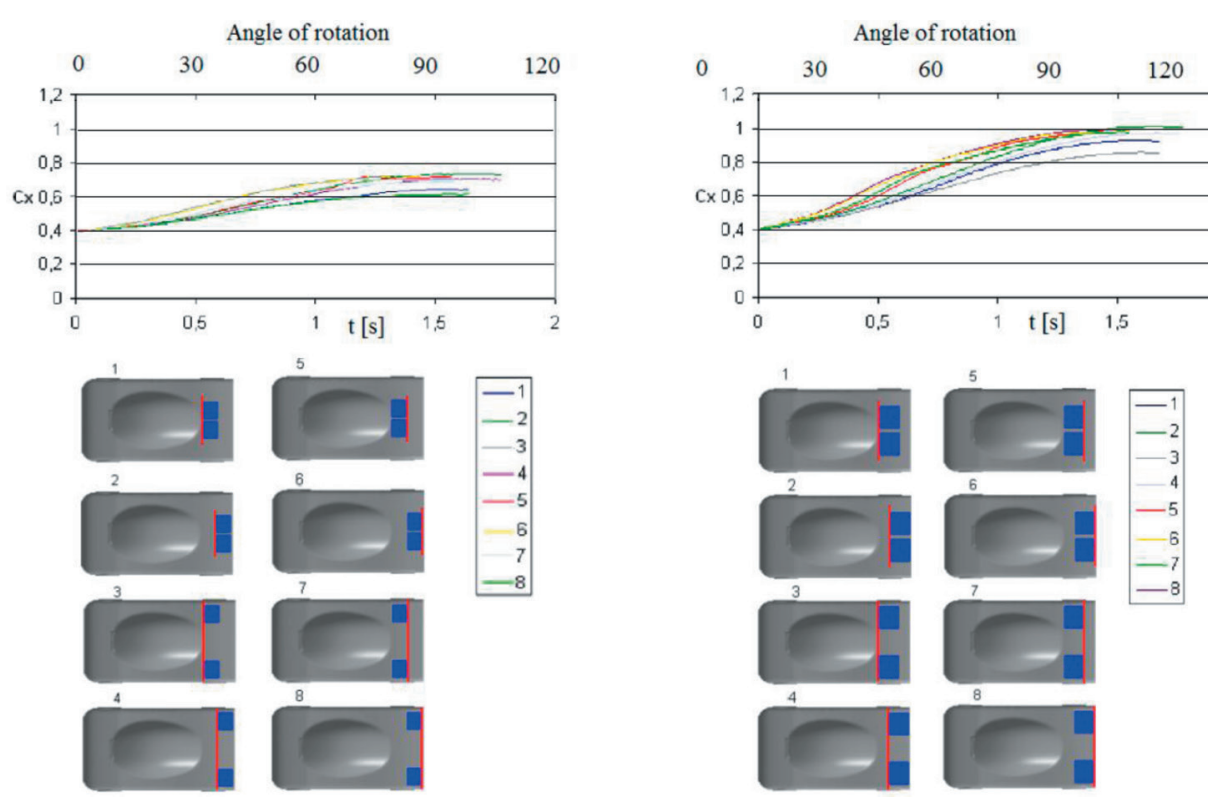

Fig. 12. Comparison of drag generation by different flaps divided into two groups (left sketch - small flaps, right sketch - big flaps)

angle is very similar. The flaps with the position of rotation axis in the back generate a greater drag, also at lower angle of rotation.

The pressure distributions on the car surface at car symmetry plane, shown in Fig. 13, illustrate the great differences between the flap located closer to the car center and that located on the end edge of the car.

To clarify the unusual variation of downforce generated by the flaps with hinges at downstream end of the flap, we concentrated investigation on flow visualization. The shape of pathlines over the partially deflected flaps at two characteristic flap angles are shown in Fig 14.

To explain the phenomenon of delay in occurrence of aerodynamic lift forces for opening angles smaller than 30 degrees for the flaps with the axis of rotation on the rear edge, the pathline shapes were analyzed for the flaps positioned closer to the center of the vehicle. It is easy to notice the flow reattachment on the upper surface of flaps at low opening angles. After exceeding the critical opening angle, the flow separates on the leading edge of the flap, and finally reattaches on the car body behind the flap.

Careful analysis of pathlines shows an attached flow on the top surface of the flap for angles lower than $30 \mathrm{deg}$. The attached flow generates low pressure on the top flap surface compensating action of high pressure area on the bottom flap surface. For higher flap deflection angles, flow separates on the flap leading edge. 

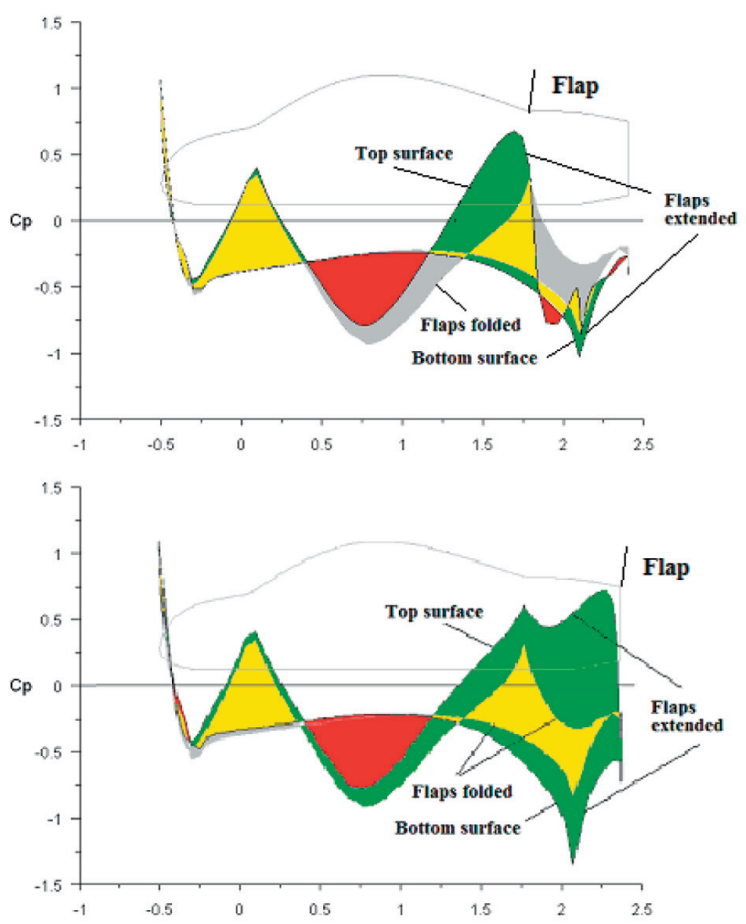

Fig. 13. Comparison of pressure distribution on the car surface at symmetry plane for two different flap positions

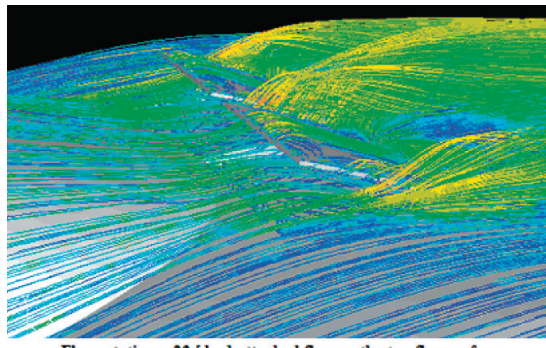

Flap rotation $=\mathbf{2 3}[\mathrm{deg}]$ attached flow on the top flap surface

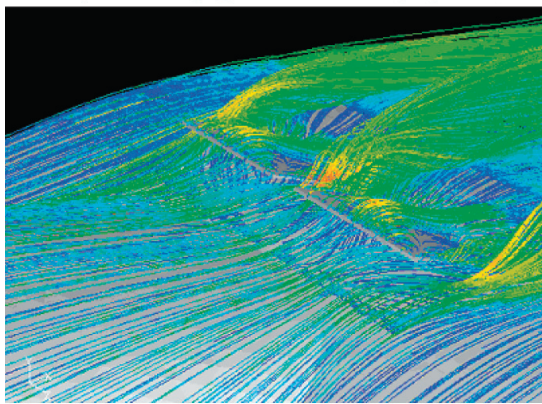

Flap rotation $=29[\mathrm{deg}]$ separated flow on the top flap surface

Fig. 14. Visualization of the flow structure generated over flaps with back position of rotation axis at low opening angle and over critical opening angle 


\section{Movable flaps located on the rear edge of the car body}

After analysis of many flap configurations, it has become clear that the most promising one is the flap with axis of rotation located on the rear edge of the car body. In such a configuration, the flap can have a start position on the rear side of the car body. The flaps had the dimensions: $0.70 \mathrm{~m}$ length and $0.29 \mathrm{~m}$ width (surface area of $2030 \mathrm{~cm}^{2}$ ). During the first phase of rotation, the flap is located in the wake formed behind the car body.
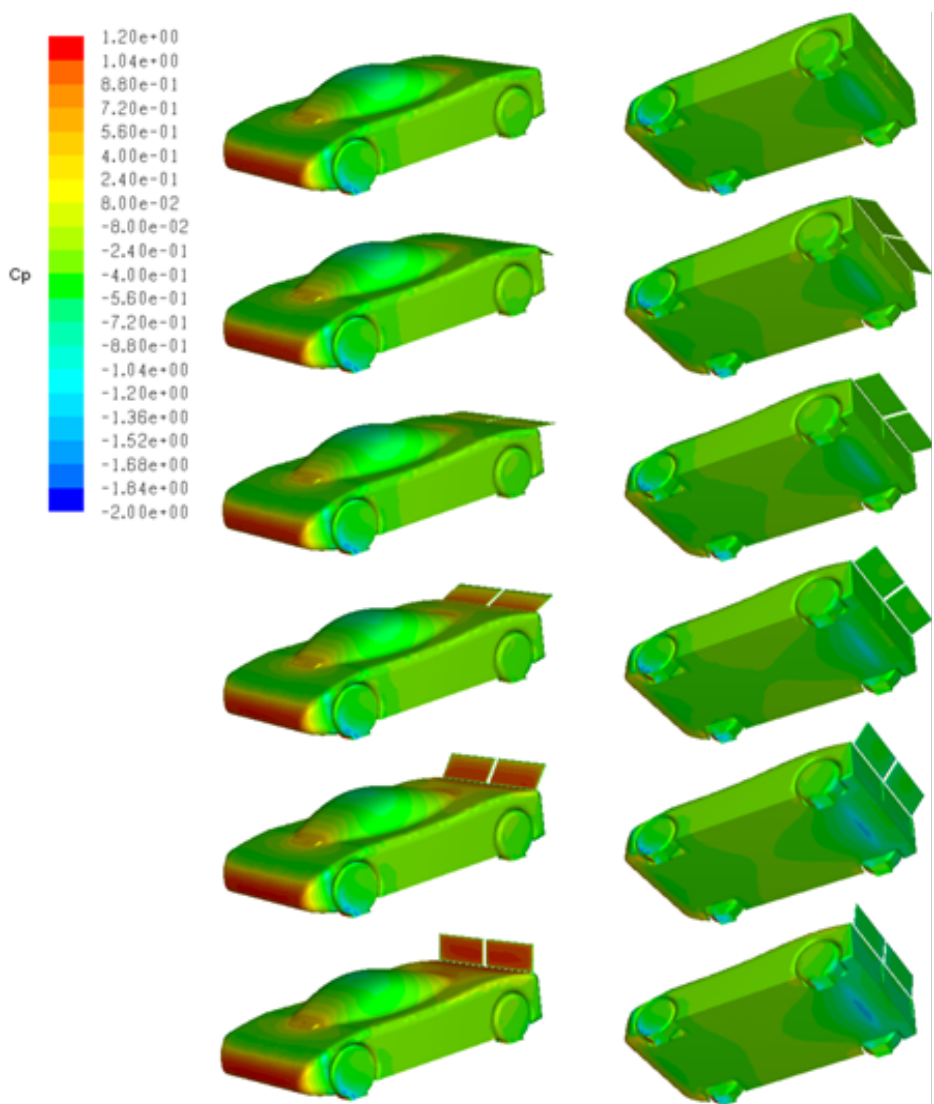

Fig. 15. Visualization of pressure distribution on the body (top and undertray) at the successive phases of the flap opening

Changes in the distribution of the pressure coefficient at the axis of symmetry of the vehicle are shown on the chart in Fig. 15. One can notice significant changes in the pressure coefficient on the uper and bottom part of the vehicle body. Comparing Fig. 13 and Fig. 15 one can easily notice strong consistence between flap position and generation of strong underpressure in the diffuser part of the undertray and areas of increased pressure on the top vehicle surface. 


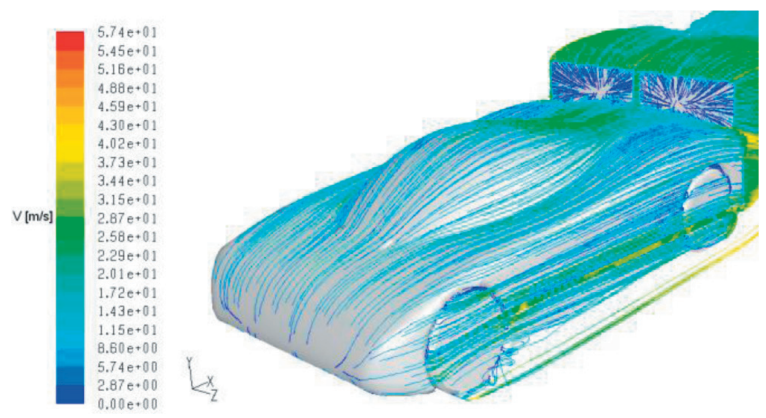

Fig. 16. Pathlines near the car body with rear flaps in fully extended position

Visualization of the flow around the car with flaps fully extended shown in Fig. 16 in the form of pathlines near the car body indicate smooth, undisturbed flow pattern around the car body.

Comparison between flow structure around the clean body and over the car with fully extended flaps is depicted in Fig. 17. Taking into account dif-

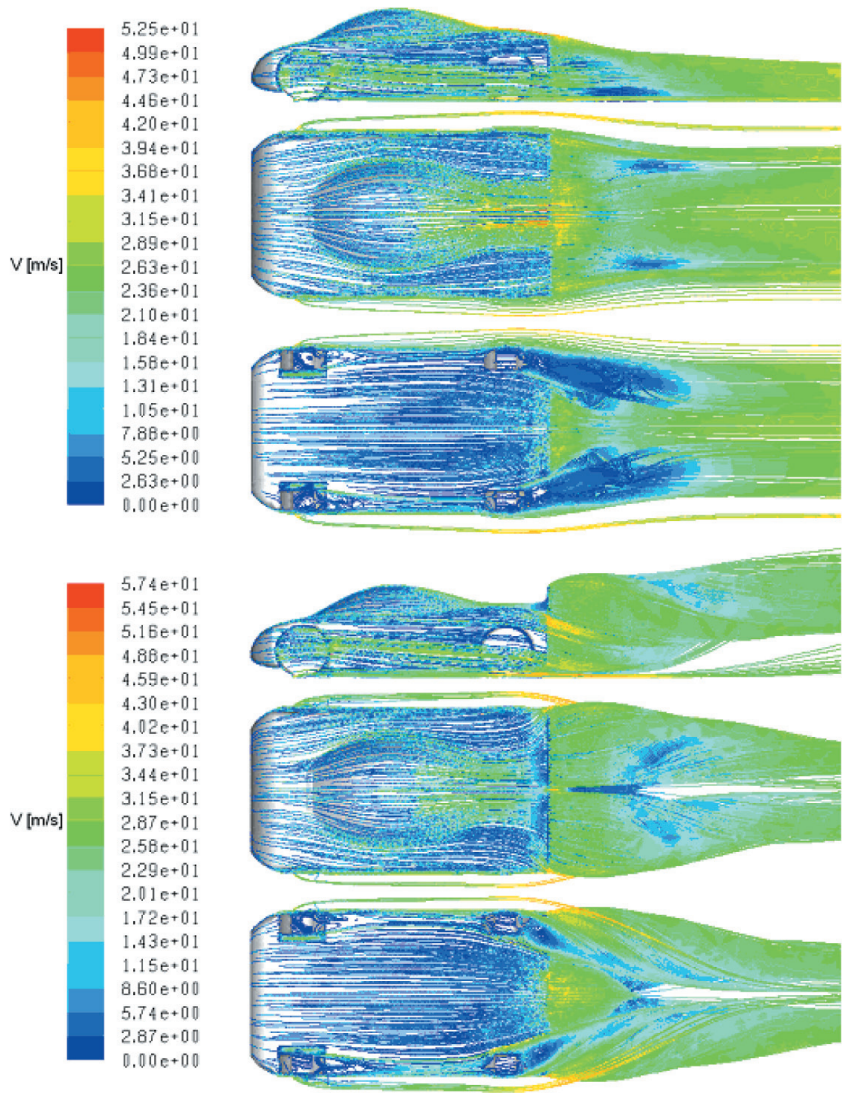

Fig. 17. Visualization of the flow structure over the reference body and car with flaps fully extended 
ferences in pathline shapes one can clearly see a dramatic change in the flow structure behind the car body with minor changes of flow pattern around the body. Opening of the flap causes that the flow deviates up behind the car, creating two large vortices.

Taking into account the observed rather high efficiency of such a flap configuration, we have tested flaps with smaller dimensions. Pressure distributions in three tested cases are shown in Fig. 18. Table 1 contains results of investigation presented in numerical form, and Fig. 19 shows it in the form of a graph.

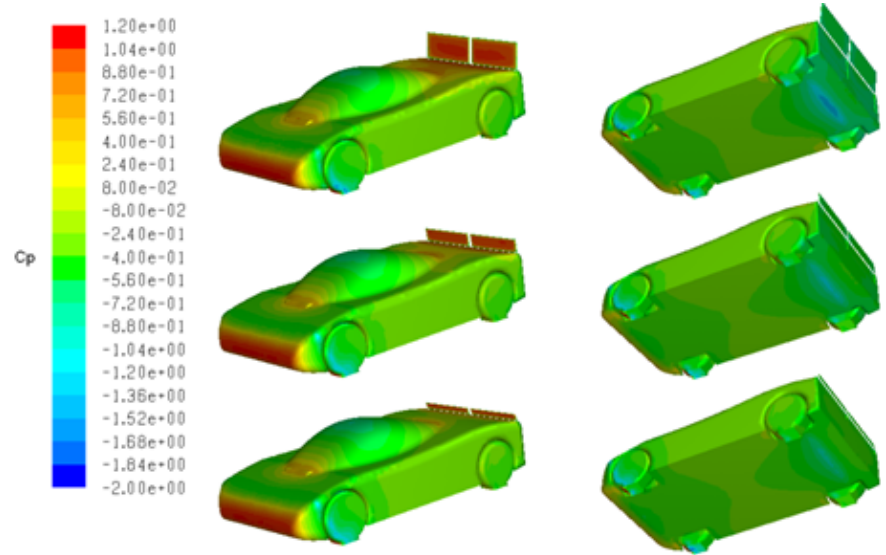

Fig. 18. Comparison of pressure contours on top surface and underbody of car equipped with flaps of full size, 0.5 size and 0.33 size

Table 1

\begin{tabular}{|c|c|c|}
\hline Flap size (relative to the biggest) & $\mathrm{Cl}$ & $\mathrm{Cx}$ \\
\hline 1 & -0.87 & 1,1 \\
\hline 0.5 & -0.51 & 0.72 \\
\hline 0.33 & -0.17 & 0.53 \\
\hline no flap & +0.20 & 0.40 \\
\hline
\end{tabular}

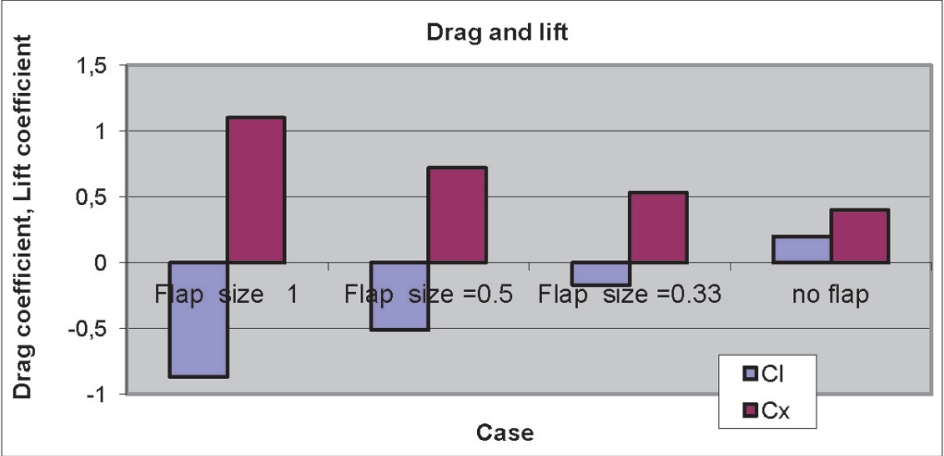

Fig. 19. Variation of drag and lift force coefficients with size of the flap 
The dynamics of the flap operation is presented in Fig. 20. One can notice the ranges of lower drag generation and the areas of lift generation instead of downforce.

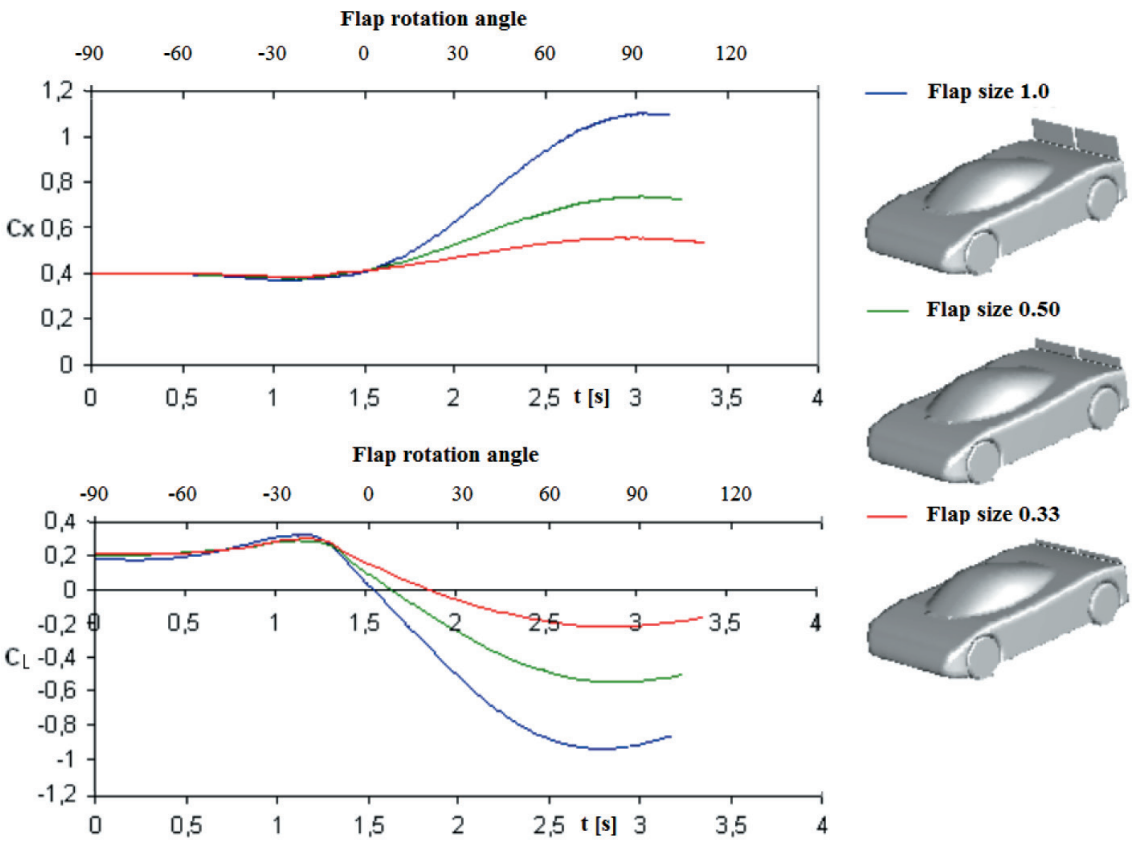

Fig. 20. Variation of the drag and lift coefficients with angle of flap rotation and flap size

\section{Front flaps}

An interesting example of application of front flaps is the construction of the super car Pagani Huayra. Beside of rear flaps, the car is equipped with movable flaps located in front part of the body. Aerodynamic characteristics of the car with simple front flaps have been investigated. Two configuration of flaps shown in Fig. 21 were tested. The flaps had the same dimensions and were located in the same place, but differed in position of axis of rotation. The results of simulations are presented in Figures 22-25.

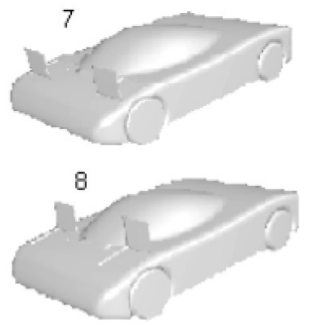

Flaps - front position of rotation

Flaps - back position of rotation

Fig. 21. Front flaps configuration 


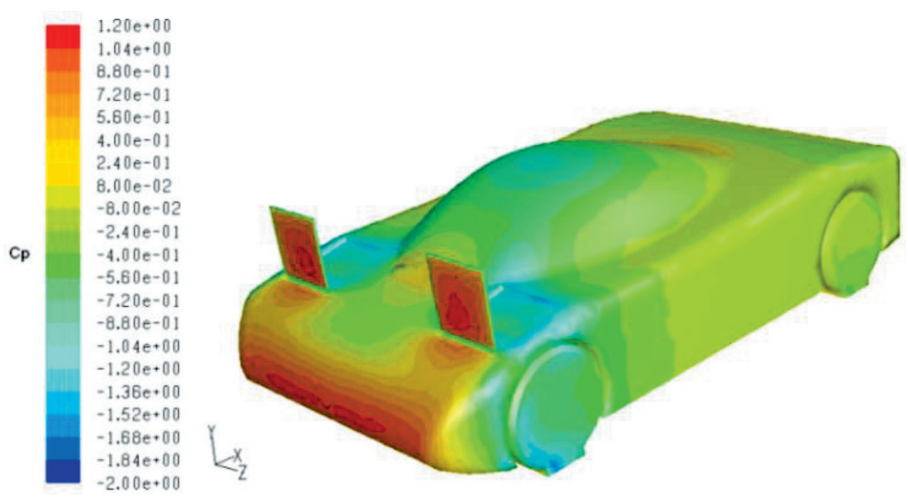

Fig. 22. Pressure distribution on the car body with fully extended front, front-hinged flaps

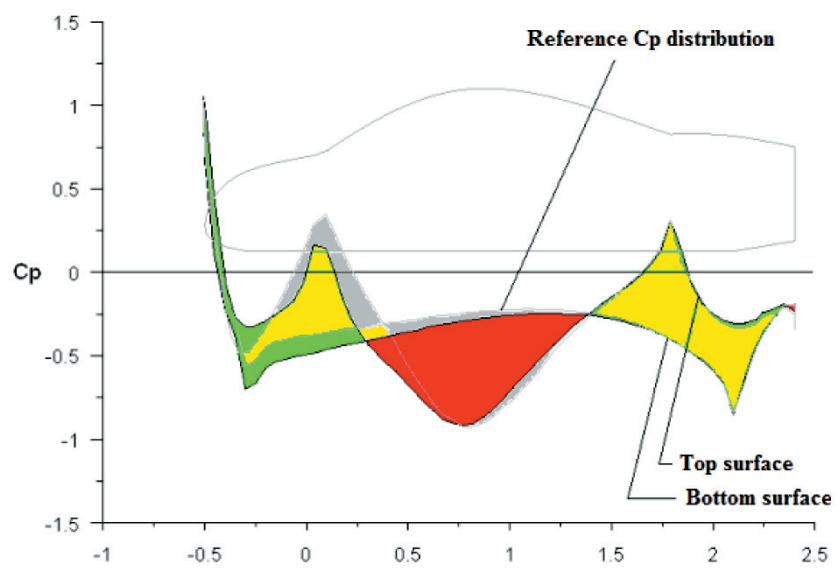

Fig. 23. Comparison of the pressure coefficient distribution on the car surface at symmetry plane in the case of opened and closed front flaps

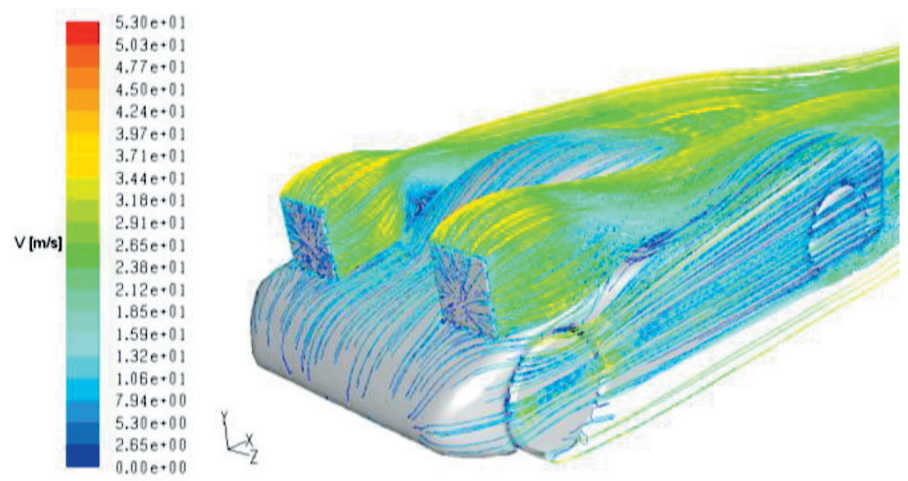

Fig. 24. Visualization of the flow structure over the car with fully extended front, front-hinged flaps (pathlines) 


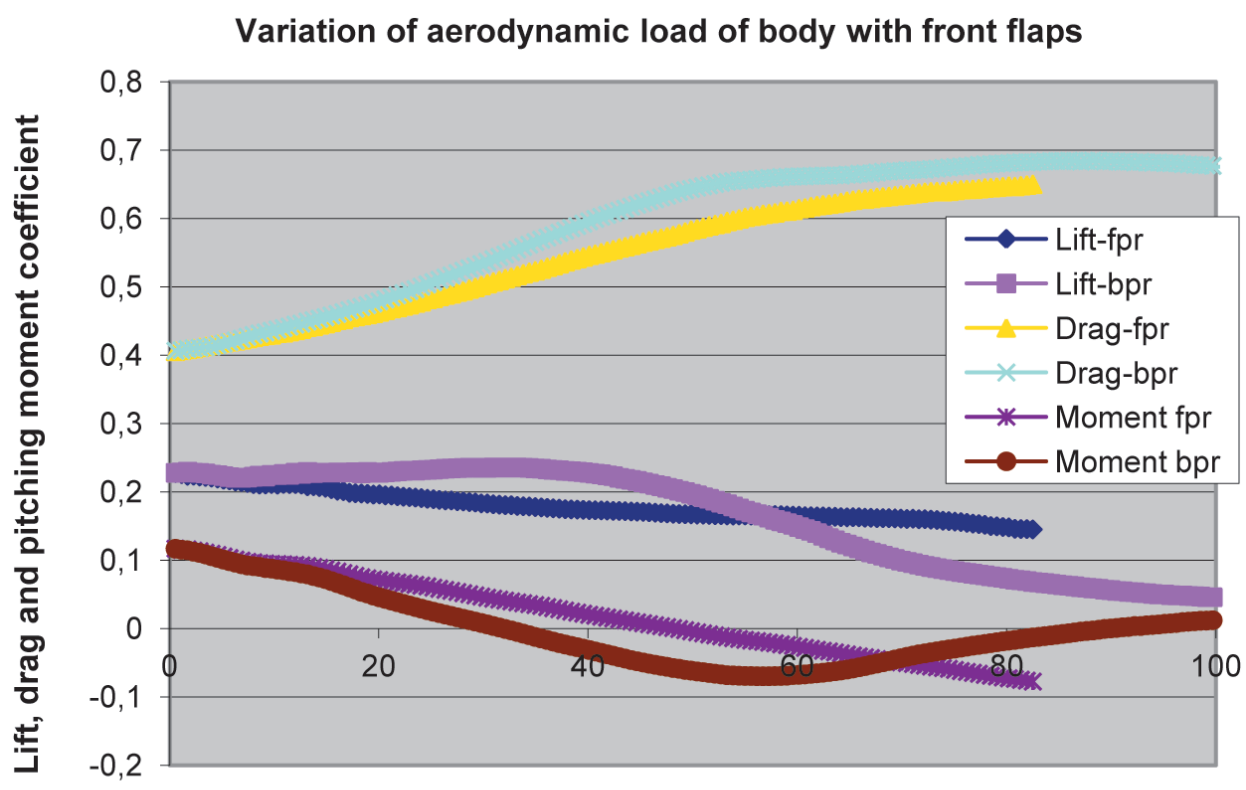

Flap rotation angle [deg]

Fig. 25. Aerodynamic characteristics of car body with different flaps configuration (front and back position of flaps rotation axis) ( $\mathrm{fpr}$ - front position of rotation axis, rpr - rear position of rotation axis)

Analyzing Fig. 25 one can again notice that the lift force values for flaps with back position of rotation axis are constant up to flap deflection angle near $40 \mathrm{deg}$. The increase in the lift generated by flap with front rotation axis position is linear, but the values of lift force are rather small. The downforce generated on the flap is only slightly higher than the lift force generated on the car body by the low pressure area downstream the flap. The low pressure area is distributed on the surface bigger than the area occupied by the flap.

The flap with back position of rotation axis, at high angles of deflection, generates bigger downforce than the flap with front axis of rotation, because the high pressure area upstream of the flap is bigger (the flap in fully opened configuration is located in a longer distance from the car front). It seems that the flaps located in the front part of the car body are not efficient as the devices generating downforce. 


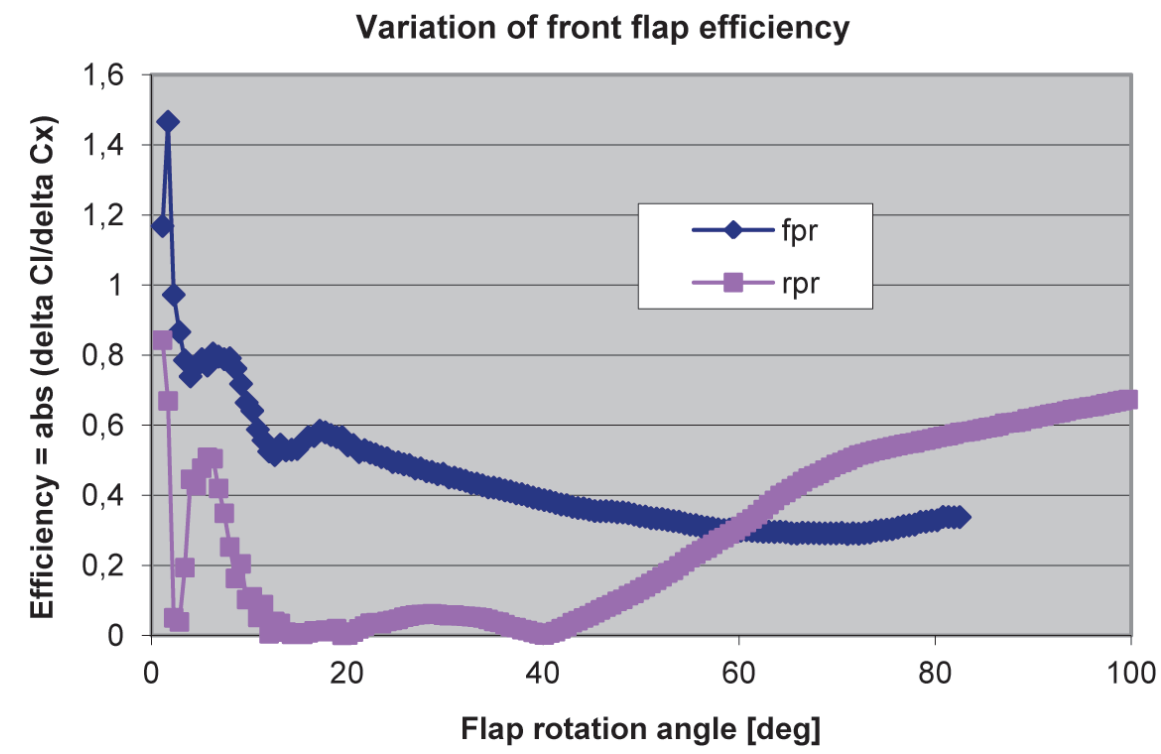

Fig. 26. Efficiency of lift generation in relation to drag at different flap deflection angles and position of flap rotation axis (fpr - front position of rotation axis, $\mathrm{rpr}$ - back position of rotation axis)

\section{Best configurations}

From many tested flaps configurations we have selected three best solutions. In Fig. 27 there is presented variation of the lift force coefficient versus flap rotation angle. It should be noticed that the definition of flap rotation angle is different.
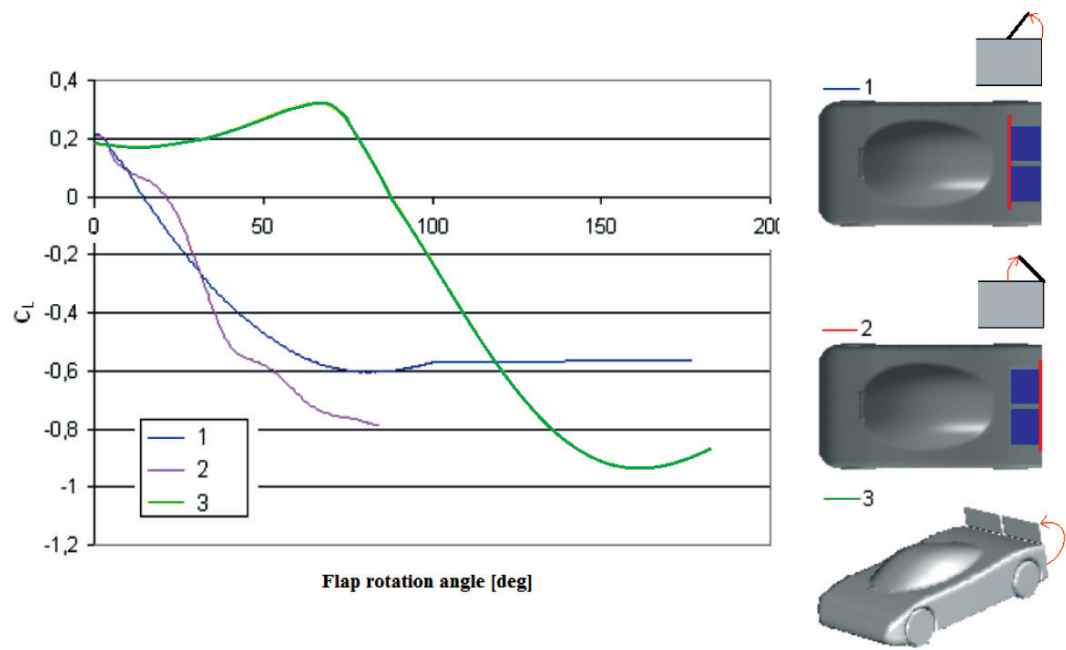

Fig. 27. Comparison of aerodynamic characteristics of the best flap configurations 


\section{Flaps extended asymmetrically}

In Fig. 28, there are shown aerodynamic characteristics of the car with flaps opened asymmetrically.
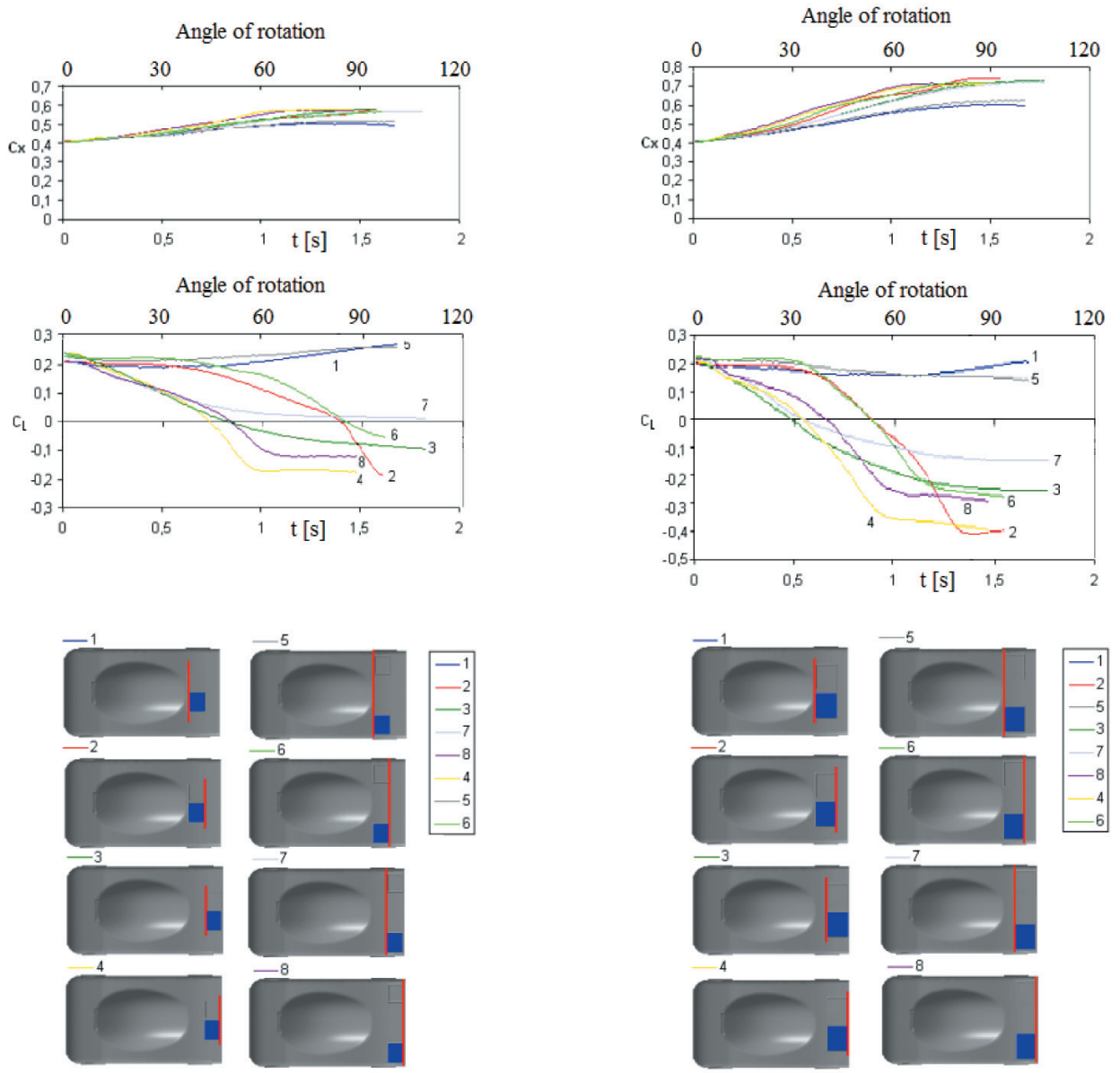

Fig. 28. Comparison of drag and lift generation by different flap configurations divided into two groups (left sketch - small flaps, right sketch - big flaps)

\section{Conclusions}

Movable aerodynamic elements of the car body were already used in the early days of racing cars $[4,5,6,7,11]$. In addition to moving wings, movable flaps were used on the Porsche 917, in 1969 year model. Flaps were placed on the rear edge of the body, which is in line with the present results of numerical simulations. 
A moving airbrake, in the form of a single large flap, with the axis of rotation on the rear edge of the flap, used in 1955 by Mercedes-Benz in 300 SLR model, was an effective aerodynamic component of the vehicle braking system, supporting big drum brakes and increasing the load on the rear axle [11]. The modern amateur tailgate Mazda MX-5 lifting system is another example of flap aerodynamic brake. Mitsubishi HSR II with large flaps on the back of the body is a classic example of moving aerodynamic parts application showing the high efficiency of that solution [11]. Air brakes are quite commonly used also in high-speed sports cars.

Moving beyond rear edge of the vehicle, the extending spoiler in the Mercedes $\mathrm{C} 112$, is the next example of the movable aerodynamic technology efficiency.

Pagani Huayra has a movable flaps on the back and front of the body. Based on the results of calculations presented in the paper, it seems that tailgate flaps are quite effective, but front flaps appear to be beneficial for improving the cooling system, but do not fulfill the role of elements that generate aerodynamic downforce.

Ferrari uses sliding flap beyond the body which, according to our investigations, is very efficient.

Moving flaps placed on a fast car body can greatly affect its aerodynamic characteristics. The way the flaps generate the aerodynamic forces strongly depends on the position of the flap on the car body and the position of the flap's axis of rotation.

One of interesting and important results of recent investigation is finding that there exist configurations of flap positions that don't generate the downforce as expected. Depending on whether the rotation axis is located at the front or rear edge of the flap, there are two types of aerodynamic characteristics. When the rotation axis is arranged at the front edge of the flap, the changes in lift force are smooth, and proportional to the opening angle of the flap. When the rotation axis is disposed at the rear flap edge, there is a delay in generating the lift force. It only increases beyond a certain opening angle. There is still further dependence on the position of flaps. Flaps on the back of the body generate more downforce and its changes are smoother. Flaps placed closer to the center of the vehicle produce less downforce and need to open at least to 30-degrees to start generation of the aerodynamic downforce.

Flaps located on the car body generate the downforce in two ways. On the one hand, a flap generates pressure difference between the bottom and top flap surface which results in downforce generation. On the other hand, a deflected flap strongly influences pressure distribution on the car body upstream and downstream of the flap. Typically, a high pressure area is formed upstream of the flap, generating downforce. However, downstream of the flap, low pres- 
sure zone develops resulting in lift force generation. So, the preferable one is flap location forming the greatest high pressure area upstream, and the lowest area of low pressure downstream. It means that the flaps should be located near the car body end.

The flaps with back position of rotation axis, at high angle of deflection, generate greater downforce mainly due to bigger area of high pressure upstream flaps, and simultaneously smaller low pressure zones downstream. Unfortunately, due to the flow attached to the top flap surface, at low deflection angles (less 30-40 deg) the downforce is not generated. Due to these phenomena, movable flaps with back position of flap rotation axis should be applied mainly as aerodynamic braking devices. Such flaps generate higher drag at lower flap deflection angle. Such a flap configuration requires fast acting actuators to overcome delay in downforce generation at low flap deflection. The good point is that aerodynamic forces tent to open the flap, so the actuators may be weaker, but the limiters should be stronger.

Flaps can be used as very effective air brakes. In this case, one should use configuration with the axis of rotation of the flap on the rear edge, because it generates more of braking power and more downforce and, additionally, the force is applied more in the back. The delay in the occurrence of downforce is not so important.

Flaps can be used as components improving vehicle stability at high speeds. In this case, the flap may be used with the axis of rotation at the front or rear edge.

Flaps can be used as active elements damping body movements. In this case, one should rather use flaps with front position of the rotation axis due to the smooth and nearly linear characteristic of the of aerodynamic downforce.

The best solution is to place flaps behind the vehicle rear edge. They give the highest values of force in relation to the flap surface, and the force changes are smooth. In certain driving conditions, they allow for a slight reduction of aerodynamic drag.

The flaps placed on the car body, in most cases, in addition to the expected downforce, generate lifting forces on other surfaces. The flaps located behind the body do not produce such negative effects.

Manuscript received by Editorial Board, January 02, 2015

final version, August 02, 2015

\section{REFERENCES}

[1] Genta G.: Motor Vehicle Dynamics - Modeling and Simulation, World Scientific, 1997.

[2] Gugała M., Piechna J., Mueller J.D.: The Design of Formula SAE Car Body Aerodynamics Using ANSYS Fluent Optimisation Tools, Automotive Simulation World Congress, taking place on October 29-30, 2013 at the Steigenberger Aiport Hotel in Frankfurt/Main, Germany. 
[3] Gullberg P., Loefdahl L., Qiu Z.: Influence of Aerodynamics on the Fatal Crash in Le Mans 1955, EASC 2009, 4th European Automotive Simulation Conference, Munich, Germany, 6-7 July 2009, pp 9-20.

[4] Hucho W. H.: Aerodynamics of Road Vehicles, 4th ed., SAE International, Warrendale, Pennsylvania, 1998.

[5] Hucho W. H.: Aerodynamika samochodu. Od mechaniki przepływu do budowy pojazdu. WKŁ, Warszawa 1988.

[6] Katz J., Race Car Aerodynamics: Designing for Speed, 1995, Robert Bentley.

[7] Katz J.: Aerodynamics of Race Cars, Annu. Rev. Fluid Mech. 2006. 38: 27-63.

[8] Lanfrit M.: Best practice guidelines for handling Automotive External Aerodynamics with FLUENT Version 1.2 (Feb 9th 2005).

[9] Larsson T.: 2009 Formula One Aerodynamics - BMW Sauber F1.09 - Fundamentally Different, EASC 2009, 4th European Automotive Simulation Conference, Munich, Germany, 6-7 July 2009, pp 9-20. 1-7.

[10] Lombardi G., Maganzi M., Cannizzo F., Cardile E.: Use of the CFD for the Aerodynamic Optimization of the Car Shape: Problems and Application, EASC 2009, 4th European Automotive Simulation Conference, Munich, Germany, 6-7 July 2009, pp 9-20, 59-70.

[11] Piechna J.: Podstawy aerodynamiki pojazdów, WKŁ. Warszawa 2000.

[12] Piechna J., Rudniak L., Piechna A.: CFD Analysis of the Central Engine Generic Sports Car Aerodynamics, EASC 2009, 4th European Automotive Simulation Conference, Munich, Germany, 6-7 July 2009, pp. 95-106.

[13] Piechna J., Janson T., Sadowski P., Tudruj S., Piechna A., Rudniak L.: Sports Car with Movable Flaps and Deformable Airbags, Automotive Simulation World Congress, taking place on October 29-30, 2013 at the Steigenberger Aiport Hotel in Frankfurt/Main, Germany.

[14] Pietrzak P., Piechna J.: Numerical investigation of the controllable wing stall caused by the air injection, The Archive of Mechanical Engineering, Vol. LX, 2013, No. 2, pp. 199-216.

\section{Analiza numeryczna charakterystyk aerodynamicznych szybkiego samochodu $\mathrm{z}$ ruchomymi elementami nadwozia}

Streszczenie

W pracy przedstawiono wyniki numerycznej analizy charakterystyk aerodynamicznych szybkiego samochodu wyposażonego w ruchome elementy aerodynamiczne - klapy. Badano wpływ wielkości, kształtu, położenia, kąta nachylenia ruchomych klap, na docisk aerodynamiczny pojazdu i siły oporu aerodynamicznego. Obliczenia wykonano za pomocą oprogramowania CFD ANSYS-Fluent. Analizowano nieustalony przepływ płynu nieściśliwego z modelowanym wpływem turbulencji (model Spalarta-Allmarasa lub SAS), wokół nadwozia, podczas ruchu klapy. Wyniki obliczeń przedstawiono w postaci rozkładów ciśnienia, przebiegu linii prądu, zmian sił w funkcji kąta obrotu klapy. Analizowano zarówno wielkości sił aerodynamicznych powstających na nadwoziu z klapami jak i przyczyny ich powstawania. Pokazano przykłady skutecznych konfiguracji klap jak i przykłady konfiguracji nie generujących aerodynamicznej siły docisku. Przedstawiono porównanie zmian sił występujących przy różnych kątach otwarcia klap, rozkłady ciśnień, wizualizacje przepływu wokół nadwozia. Przedstawiono fizyczne przyczyny obserwowanych nietypowych charakterystyk działania klap. Oszacowano praktyczną przydatność poszczególnych rozwiązań do kontroli stabilności szybkiego samochodu. 